\title{
La lectura paronomástica: Freud y Lacan por Haroldo de Campos
}

\section{The paronomastic reading: Freud and Lacan by Haroldo de Campos}

\author{
Rosario LÁZARO \\ Pós-Graduação em Estudos da Tradução (PGET) \\ Universidade Federal de Santa Catarina (UFSC) \\ Walter Carlos COSTA \\ Pós-Graduação em Estudos da Tradução (PGET) \\ Universidade Federal de Santa Catarina (UFSC)
}

RESUMEN: Este artículo propone una lectura de la relación que establece Haroldo de Campos con el psicoanálisis en el ensayo "O afreudisíaco Lacan na Galáxia de lalíngua (Freud, Lacan e a escritura)”, teniendo como eje articulador la traducción paronomástica y las implicaciones en su visión sobre el lenguaje. Para tal fin, en primer lugar define la paronomasia como figura retórica y su lugar dentro de la poesía concreta. A continuación, destaca algunos de los postulados de la poética de la traducción concreta presentes en el mencionado ensayo de Campos, buscando evidenciar hasta qué punto el acercamiento a Freud y a Lacan se produce por la vía de una poética basada en la paronomasia.

PALABRAS CLAVE: Psicoanálisis. Haroldo de Campos. Paronomasia.

ABSTRACT: This article presents a reading of the relationship Haroldo de Campos establishes with the psychoanalysis in his essay " $\mathrm{O}$ afreudisíaco Lacan na Galáxia de lalíngua (Freud, Lacan e a escritura)”, having as axis the paronomastic translations and its implications for his conception of language. For that, it defines paronomasia as a rhetoric figure and places it within the concrete poetry. Then it foregrounds some principles of the translation poetics in Campos's essay, trying to show how far this approach to Freud and Lacan is due to a poetics based mainly on the paronomasia.

KEYWORDS: Psychoanalysis. Haroldo de Campos. Paronomasia. 


\section{Introducción}

El 22 de setiembre de 1989, el día anterior a la conmemoración de los cincuenta años de la muerte de Sigmund Freud, el suplemento Ilustrada de la Folha de São Paulo, publicaba un artículo conmemorativo. En el mismo, leemos la siguiente declaración de Haroldo de Campos, entrevistado para la ocasión:

Freud, como Marx y Nietzsche, es una de esas figuras que realizaron un corte en el pensamiento contemporáneo. El problema no es creer en el psicoanálisis, como si fuera un sucedáneo de religión. Es conocer la importancia de su papel en el estudio del hombre, de su sexualidad y de su imaginario. Para mí, como poeta, es fundamental la relación de Freud con el lenguaje, con el sueño, la broma, el chiste, aspecto que adquiere evidencia con Lacan, pero que ya había sido enfatizado por el teórico suizo de literatura Walter Muschg. En un ensayo de 1930, compara a Freud con el poeta alemán Morgenstern y con los surrealistas, en términos de sensibilidad con la lingüística. ${ }^{1}$

Entre los muchos consultados, el testimonio de Campos llama la atención por no ser demasiado coincidente con el título "Intelectuais ainda duvidam da psicanálise" [Intelectuales aún dudan del psicoanálisis], como sí lo son muchos de los testimonios de personalidades como Julio Bressane, Ignácio de Loyola Brandão y un Antônio Houaiss con una postura más integradora.

\footnotetext{
1 "Freud, como Marx e Nietzsche, é uma dessas figuras que operaram um corte decisivo no pensamento contemporâneo. O problema não é crer na psicanálise, como se ela fosse um sucedâneo de religião. É conhecer a importância de seu papel no estudo do homem, de sua sexualidade e de seu imaginário. Para mim, como poeta, é fundamental a relação de Freud com a linguagem, com o sonho, o trocadilho, o chiste, aspecto que ganha evidência com Lacan mas que já havia sido enfatizado pelo teórico suíço de literatura Walter Muschg. Em ensaio de 1930, compara Freud ao poeta alemão Morgenstern e aos surrealistas, em termos de sensibilidade com a lingüística". Traducción de nuestra autoría, como las que siguen cuando no se menciona el nombre del traductor.
} 
Sin embargo, lo que sobresale en sus palabras es el conocimiento acerca del asunto, donde vemos que la teoría psicoanalítica ha sido integrada a su reflexión sobre la poesía y el lenguaje. Como veremos más adelante, su lectura es la de un poeta, pero de un poeta en el cual su obra es un todo indivisible entre poesía, crítica y traducción.

En este sentido, se debe sumar que la aproximación de Haroldo de Campos al pensamiento de Sigmund Freud y de Jacques Lacan, comienza bastante antes y se evidencia en una serie de ensayos dentro de los cuales el más divulgado ha sido "O afreudisíaco Lacan na Galáxia de lalíngua (Freud, Lacan e a escritura)". Otro de los frutos de tal acercamiento es el diálogo que mantuvo Campos con Jean Laplanche, traductor de Freud al francés, ocurrido en 1993 y documentado en formato audiovisual ${ }^{2}$. Aunque el vínculo teórico con el psicoanálisis no fue tan central en el pensamiento haroldiano, como sí lo fue la lectura de Walter Benjamin, Roman Jakobson, Ezra Pound y Stéphane Mallarmé, vale anotar cómo Campos relaciona el legado del psicoanálisis con temas sobre los que venía trabajando a través de los citados autores, incorporando nuevas referencias de una forma "tentacular", declaradamente neobarroca, que signará la globalidad de su obra (por complementariedad con su militancia concreta) y sobre la que Jacó Guinsburg, en entrevista a Gênese Andrade, declarara: "[...] en la obra de Haroldo hay dos polos: por un lado, el interés por un barroquismo extremo [...] por otro [...] el concretismo, en su reducción total de la escritura"3 (GUINSBURG, 2010, p. 121). La aparente disyunción entre tales vertientes es amalgamada por el mismo Haroldo de Campos, que hablando sobre su obra en entrevista realizada en ocasión del lanzamiento de las Galáxias,

2 Titulado: "Conversa entre Laplanche e Haroldo de Campos sobre o tema da tradução", estará próximamente disponible en el sitio del Departamento de Psicoanálisis de la Red Sedes Sapientiae: http://www.sedes.org.br/ Departamentos/Psicanalise/index.php

3 “' [...] na obra de Haroldo você tem dois polos: de um lado, o interesse por um barroquismo extremo [...] de outro [...] o concretismo, na sua redução total da escritura". 
declaraba: "Que las mismas hayan podido coexistir, es algo que me demostró la inexistencia de una oposición antagónica entre barroquismo y constructivismo"4 (CAMPOS, 1984, p 25). O sea, la posición radical acerca del lenguaje y sus posibilidades, resaltando el plano de su materialidad, de los parentescos entre palabras como llaves de acceso a la lengua pura benjaminiana, será lo que acerca a Haroldo de Campos al psicoanálisis.

\section{Paronomasia \& poética de la traducción concreta}

Roman Jakobson (2004), en "On Linguistic Aspects of Translation" - al que Haroldo de Campos volviera una y otra vez a lo largo de su obra crítica -, después de una defensa de la condición traductoria esencial del lenguaje, afirma:

En poesía, las ecuaciones verbales son elevadas a categoría de principio constructivo del texto. Las categorías sintácticas y morfológicas, las raíces, los afijos, los fonemas y sus componentes (trazos distintivos) - en suma, todos los constituyentes del código verbal - son confrontados, yuxtapuestos, puestos en relación de contigüidad de acuerdo con el principio de similitud y de contraste, y transmiten así una significación autónoma. La similitud fonética es sentida como relación semántica. El pun, o para usar un término más erudito y tal vez más certero -paronomasia, reina sobre el arte poética, y ya sea su reinado absoluto o limitado, la poesía es por definición intraducible. ${ }^{5}$ (JAKOBSON, 2004. p. 142)

4 "Que elas tenham podido coexistir, é algo que me demonstrou a inexistência de uma oposição antagónica entre barroquismo e construtivismo".

5 "In poetry, verbal equations become a constructive principle of the text. Syntactic and morphological categories, roots, and affixes, phonemes and their components (distinctive features) - in short, any constituents of the verbal code are confronted, juxtaposed, brought into contiguous relation according to the principle of similarity and contrast and carry their own autonomous signification. Phonemic similarity is sensed as semantic relationship. The pun, or to use a more erudite, and perhaps more precise term - paronomasia, reigns over poetic art, and whether its rule is absolute or limited, poetry by definition is untranslatable". 
Como recuerda la entrada correspondiente a esta figura retórica en la Princeton Encyclopedia of Poetry and Poetics, la paronomasia fue el procedimiento primordial sobre el que el poeta Ezra Pound edificó su idea de "logopoeia" (PREMINGER, 1993 , p. 1005), una forma entre las tres por medio de las cuales el lenguaje es "energizado" y que, a diferencia de la "melopoeia" (fenómenos rítmicos) y la "phanopoeia" (visualidad), se basa en el impacto verbal del propio lenguaje. Claro que la paronomasia, y por ende el recurso de la "logopeia", no es tal sin la concurrencia de los otros dos, pero en todo caso señala un acercamiento a la materialidad de la lengua y la privilegia justamente por su posibilidad de desafiarla.

A este respecto:

En el lenguaje de la poesía, encontramos paronomasia [pun] lexical, paronomasia gramatical, y la forma sofisticada de paronomasia basada en palabras o frases que pertenecen simultáneamente a distintos niveles de dicción, situación o experiencia. ${ }^{6}$ (PREMINGER, 1993, p. 1005)

Debe subrayarse que desde temprano en su trayectoria, Haroldo de Campos estableció un intenso diálogo con Pound, tanto es así que fragmentos de los Cantos del poeta norteamericano fue la primera traducción que el Grupo Noigandres publicó. Justificando esa primera traducción, Campos reconoce: "[...] estábamos descubriendo el método ideogramático de los Cantos de Ezra Pound"' (COSTA, 2006, p.47). Por esa afinidad, la correspondencia de los concretos con Pound había comenzado en

6 "In the language of poetry, we find lexical puns, gramatical puns, and the sophisticated form of pun based on words or phrases which simultaneously belong to disparate levels of diction, situation or experience".

7 “O ideário dos poetas de 45, seu anti-experimentalismo, sua inclinação ao decorum e o comedimento, sua preocupação pelo clima do poema (onde tudo fosse harmonia e consonância) era algo que não nos atraía a nós três, poetas novíssimos, que admirávamos a sintaxe subversiva e o léxico enigmático de Mallarmé; que estávamos descobrindo o método ideogramático dos Cantos de Ezra Pound; que líamos com entusiasmo ao Apollinaire de Lettre-Océan y dos Calligrammes e ao Lorca das metáforas dissonantes do Poeta en Nueva York". 
1953, un año después de que el Grupo Noigandres fuera fundado, lo que explica que la traducción de los Cantos de Ezra Pound se inscriba como una tarea "fundacional" de la poesía concreta en su primera década de acción, inaugurando una línea de traducción de autores con los que tuvieron afinidad y que, siguiendo a Pound (que lo había tomado del etnógrafo Leo Frobenius), denominaron paideuma.

La entrada correspondiente a paronomasia en el Diccionario de Retórica y Poética, de Helena Beristain (1995, p.385), indica:

Figura que consiste en aproximar dentro del discurso expresiones que ofrecen varios fonemas análogos (paronimia) [... Se trata de una metábola de la clase de los metaplasmos porque involucra elementos morfológicos de las palabras. Se produce por adición repetitiva de varios fonemas en palabras o en frases que poseen significados en algún grado diferentes, por lo que pueden ofrecer una homonimia parcial [...] y una equivocidad parcial $[\ldots]$.

Beristain también se detiene en otros aspectos de la paronomasia, como la tensión resultante entre forma y sentido, que podría llegar en momentos a resultar paradójica. Particular interés tiene una variación de la paronomasia que se construye sobre el parentesco etimológico de varias palabras, denominada "parequesis" y que Campos explorará con énfasis tanto en sus traducciones como en sus escritos críticos sobre el tema. De estos últimos, vale la pena destacar el ensayo "Transluciferação Mefistofaústica", de 1980, publicado en Deus e o Diabo no Fausto de Goethe (1981). Allí, Campos (1981, p. 182) defiende una traducción donde:

[...] por fuerza del contagio de significantes convergentes y coincidentes, se reconstruya y se motive, fragmentariamente, en el interior del texto, haciendo del azar necesidad y transformando la 'falsa' o 'pseudo' etimología [...] en designación adánica, inaugural”"

8 “"...] por força do contágio de significantes convergentes e coincidentes, se 
La traducción como operación paronomástica generalizada centrada en la equivalencia de la función poética, de Jakobson, es llevada a cabo por Campos en su traducción de esa "área sémica de tonos sombríos y tristes" (CAMPOS, 1981, p 182). En este sentido, lo que propone es una operación que se sustente en el efecto icónico del texto traducido, destacando que es en la traducción que aparece con más fuerza que en otras operaciones literarias la noción de "mimesis", como "producción de la diferencia del mismo"10 (CAMPOS, 1981: 183). Los hallazgos de traducción confirmarían una reconciliación profunda entre las lenguas distintas, referencia a la "lengua pura" benjaminiana.

En cuanto a su poesía, un ejemplo de paronomasia, entre muchos, lo encontramos en el poema "nascemorre" (de Fome de Forma, 1958) (CAMPOS, 2000, p. 49):

se

nasce

morre nasce

morre nasce morre

renasce remorre renasce

remorre renasce

remorre

re

\section{re \\ desnasce \\ desmorre desnasce \\ desmorre desmorre desnasce}

nascemorrenasce

morrenasce

morre se

Figura 1

reconstrua y se motive, fragmentariamente, no interior do texto, fazendo do acaso necessidade e transformando a 'falsa' ou 'pseudo' etimologia [...] em designação adâmica, inaugural".

9 "[...] área sêmica de tons sombrios e tristes".

10 "[...] produção da di-ferença do mesmo". 
Como recuerda la Princeton Encyclopedia of Poetry and Poetics, el recurso de la paronomasia fue usado ampliamente en la retórica clásica, medieval y renacentista, aunque luego fuera denostado durante el clasicismo como no perteneciente al lenguaje poético elevado, rechazo que se extiende hasta el modernismo ((PREMINGER, 1993: 1005). El gesto de Haroldo de Campos, por la vía de, entre otros, Ezra Pound, Gregório de Matos, Oswald de Andrade, James Joyce, Mallarmé, reivindica una cierta tradición, aunque no predominante, de invención con el lenguaje.

El profesor y traductor portugués Manuel Portela, en un artículo inédito escrito de 2003, y titulado justamente "Haroldo de Campos (1929-2003): a estrutura paronomásica do universo", observa:

La paronomasia constituye un recurso psicolingüístico fundamental para unificar los campos textuales de la creación y de la traducción. Para la estética concretista, la dinámica de combinación sintáctica por cruces y atracciones fónicas y gráficas se estableció como principio de composición [...]. Por medio de estos procedimientos, incluso a nivel ideológico puede verse como objeto de un arte combinatorio que destruye y reconstruye la textura de inferencias y recurrencias que garantizan la cohesión discursiva. La poética concreta trabaja la materialidad estructural y psíquica del signo, ligando sus propiedades lingüísticas formales y el procesamiento cerebral de tales propiedades. Por ello, es tanto una poética de la lengua hablada y de la lengua escrita, como de la audición y de la lectura. ${ }^{11}$ (PORTELA, 2003, sin paginación)

11 "A paronomásia constitui um recurso psicolinguístico fundamental para
unificar os campos textuais da criação e da tradução. Para a estética concretista,
a dinâmica de combinação sintáctica por cruzamentos e atracções fónicas e
gráficas estabeleceu-se como princípio de composição [...]. Por via destes
procedimentos, mesmo o nível ideológico pode ver-se objecto de uma arte
combinatória que destrói e reconstrói a textura de inferências e recorrências
que garante a coesão discursiva. A poética concreta trabalha a materialidade
estrutural e psíquica do signo, ligando as suas propriedades linguísticas formais
e o processamento cerebral dessas propriedades. Por isso é tanto uma poética 
La unificación de la creación se realizaría en Haroldo de Campos, según Portela, por la "proyección del eje paradigmático sobre el eje sintagmático", proponiendo un texto que posee las instrucciones para "leerse a sí mismo". El resultado de este procedimiento en el campo de la traducción -“transcreación”- sería un acercamiento a los "procesos clásicos y barrocos de imitación y variación". Ya en el campo de la creación poética, para Portela el riesgo último sería que: "al matematizar la lengua, haciendo de los poemas estructuras de metadatos, el poema concreto permanece muchas veces encerrado en la autorreferencialidad de sus herramientas verbales"12 (PORTELA, 2003, sin paginación).

\section{Qué Lacan y qué Freud: estética del fragmento y crítica vía traducción}

A partir de la apropiación vía paronomasia que realiza Haroldo de Campos en sus traducciones -y en sus críticas vía traducción, procedimiento del cual los libros O Arco-Íris Branco: Ensaios de Literatura e Cultura, de 1997, y el póstumo $O$ segundo arco-íris branco, de 2010, son ejemplos significativos-, cabe preguntarse qué Lacan y qué Freud son los que Haroldo de Campos advierte y privilegia. Cabe resaltar que estamos frente a un poeta, crítico y traductor menos polémico que en la primera fase de la poesía concreta; ahora sus textos pasan a ser más y más repletos de referencias a un amplio universo de autores, y a su propia producción anterior, en un interminable juego barroco en el que la paronomasia tiene un papel preponderante. Barroco, como ya han anotado muchos de sus críticos, es un rasgo que posee desde los primeros poemas de Auto do Possesso, de 1950, y que pasa a ser un eje de su crítica literaria, y de su escritura, su estilo.

da língua falada e da língua escrita, como da audição e da leitura".

12 "No entanto, ao matematizar a língua, fazendo dos poemas estruturas de metadados, o poema concreto permanece muitas vezes encerrado na autoreferencialidade das suas ferramentas verbais". 
La referencia al psicoanálisis en Haroldo de Campos, como se indicó, es tardía y Freud y Lacan no constituyen el núcleo "duro" de autores que contribuyen a la formulación de su poética de la traducción. Los textos en los que el autor se detiene en el asunto datan de la década del '80. "Barrocolúdio: transa chim”, es de 1988, "O afreudisíaco Lacan na Galáxia de lalíngua (Freud, Lacan e a escritura)", de 1989, e "O poeta e o psicanalista: algumas invenções linguísticas de Lacan”, están recogidos en el libro $O$ segundo arco-íris branco. Por notas a pie de página del autor, se puede saber que también preparó los textos "O sujeito, o texto e a criação", en 1985, y "Exercício de datilografia", en 1988 , y en el mismo año "O poeta no jogo da linguagem". Como se puede observar, el período de tiempo en el cual Campos se dedica al asunto es breve, pues se concentra en menos de una década, pero fructífero. El mismo coincide con la publicación de Transblanco (1986), y O Seqüestro do Barroco na Formação da Literatura Brasileira: o Caso Gregório de Matos (1989), así como ocurre algún tiempo después de la primera edición de las Galáxias (1984).

Entre los textos disponibles en $O$ segundo arco-íris branco está "O afreudisíaco Lacan na Galáxia de lalíngua (Freud, Lacan e a escritura)", donde se ponen en relación las escrituras de Freud y de Lacan, desde el punto de vista del estilo. Y es así que Campos comienza por ampliar el adagio buffon-lacaniano, proponiendo: "Le stylo c'est l'Ane", la lapicera que es el analista, juego que amplía, por paronomasia, el alcance de la máxima en francés:

Le style c'est l'homme. (Buffon)

Le style c'est l'Autre. (Lacan)

Le stylo c'est l'Ane. (Haroldo de Campos) (CAMPOS, 2010, p. 228)

La paronomasia funciona aquí en varios niveles. El primero, por la repetición de la secuencia material de los adagios anteriores, donde la variación se inserta en la repetición, por ella misma funciona, y en ella también incluye la divergencia. Sin embargo, y aquí cobra importancia la relación con la tradición y las 
instituciones, en la relación de "Ane" con "Analyste", o también "Âne-à-liste", el asno que escribe, que Lacan mismo introdujera como chiste, como Witz. Al mismo tiempo, "stylo" posee varias referencias en el plano de los escritos de Lacan, lo que hace que el término tenga una carga para nada menor. Las referencias se suceden, como testimonio de la erudición de Campos, en una escritura similar a la lacaniana, como si el objeto impregnara el vehículo que lo transporta. Campos se detiene en la consideración de Lacan de que: "[...] es toda la estructura del lenguaje que la experiencia psicoanalítica descubre en el inconsciente" 13 (LACAN apud CAMPOS, 2010, p. 231), y es allí también donde la hermana con las ideas acerca de los anagramas de un Saussure tardío, y de la paronomasia según Jakobson. Lo resultante es la puesta en diálogo con el Lacan "Góngora de la psychoanalyse", que se inserta en su linaje, en su paideuma, ahora también junto a Mallarmé, compartiendo la condición de "syntaxier" (CAMPOS, 2010, p. 233).

Ya en relación a Freud, Campos (2010) retoma la senda abierta por Walter Muschg de resaltar la veta literaria del padre del psicoanálisis, reivindicada por Lacan, afirmando:

[...] es ese Freud atento al design sintáctico del lenguaje, capaz de inclinarse con oído muy sutil (no inferior en acuidad a la escucha fonológica de un Jakobson) sobre la trama de sonido y de sentido, que está sobre todo sobrentendido en la reivindicación más honda de $\operatorname{Lacan}^{14}$. (CAMPOS, 2010, p. 234)

Se puede observar que tanto en el detenimiento en Lacan, como en Freud, el foco de Campos está en la capacidad lingüística experimental de ambos, como también lo hizo Joyce (CAMPOS,

13 "[...] é toda a estrutura da linguagem que a experiência psicoanalítica descobre no inconsciente".

14 “" ...] é esse Freud atento ao design sintático da linguagem, capaz de debruçarse com ouvido sutilíssimo (não inferior em acuidade à escuta fonológica de um Jakobson) sobre a trama do som e do sentido, que está sobretudo subentendido na reivindicação mais funda de Lacan". 
2010, p. 237). Y es por esa obsesión con el discurso en la vuelta de Lacan a Freud que Campos lo nombra como " 'afreudisíaco' Lacan" (CAMPOS, 2010, p. 236).

Otro de los experimentos en el mismo sentido que realiza Campos para desarrollar el parentesco entre los autores, y entre las lenguas, es la traducción de "WO ICH WAR, SOLL ICH WERDEN", del Freud tardío, proponiendo "LÁONDE ISS'ESTAVA DEVE'EUREI DEVIR-ME", guiado por juegos paronomásticos:

[...] operando reconcentradamente sobre los significantes y su sonido (y reencontrando en ese nivel la economía de la significancia, provisoriamente suspendida en la reelaboración explicativa del 'escriba/maestro de la verdad') ${ }^{15}$. (CAMPOS, 2010, p. 238)

Otra de las propuestas de Campos pasa por la traducción de "lalangue" lacaniana por "lalíngua", rechazando la traducción "alíngua", corriente entre los lacanianos brasileños; para Campos el prefijo "a" de "alíngua" anularía el destaque dado por Lacan en su neologismo "lalangue". Estas soluciones haroldianas, ingeniosas y resultado de un acercamiento milimétrico a fragmentos deliberadamente elegidos, son guiadas por la recurrencia a una "tradición de ruptura", según la expresión de Octavio Paz. Llegado a este punto, Campos (2010) recurre a su propio trabajo, citando las Galáxias, guiado por el parentesco entre letras, palabras, frases, autores, momentos de la historia como un continuum.

\section{Consideraciones finales}

Se podría decir que el acercamiento de Haroldo de Campos a Lacan y a Freud, sobre todo al segundo, es similar a su

15 “[...] operando reconcentradamente sobre os significantes e sua fonia (e reencontrando nesse nível a economia da significância, provisoriamente suspendida na reelaboração explicativa do 'escriba/mestre da verdade')". 
acercamiento a Walter Benjamin, por la atención al significante como forma de acceso a un trasfondo común a las lenguas; a Ezra Pound, por el recorte de fragmentos aislados de ambos autores; y a Roman Jakobson, por el uso deliberado de procedimientos paronomásticos. Algunos de los textos más creativos de Freud y Lacan pasan a ser analizados, vía traducción, como lenguaje experimental. Este lenguaje es también significativo y Campos llama la atención para la lectura lacaniana de la invención verbal joyciana en Ulysses y Finnegans Wake: esta sería como el lapso para el analista, que "puede ser leído de uma infinidade de maneiras distintas", como dice en La fonction de l'écrit", de 1973, publicado en el Seminário 20.

En la lectura de Campos la experimentación radical sobre la lengua adquiere un papel primordial, y es la que justifica su acercamiento a ciertos escritos y expresiones de Freud y Lacan; en él la estética del fragmento es funcional para la construcción de una nueva poética a partir de autores disímiles. En este sentido, Haroldo de Campos anticipa, de alguna manera, algunas discusiones que hoy en día ocurren en el ámbito de los Estudios de la Traducción y en los medios psicoanalíticos en torno a la traducción del psicoanálisis, tanto en Brasil, como en otros países.

\section{BIBLIOGRAFÍAS}

BERISTAIN, H. Diccionario de retórica y poética. México: Porrúa, 1995.

CAMPOS, H. de. A proesia de Haroldo de Campos. Entrevista realizada por Carlos Rennó. In: Primeiro Caderno. Folha de S. Paulo. 23 de octubre de 1984. Pp. 25.

.O afreudisíaco na galáxia de lalíngua (Freud, Lacan e a escritura). In: . O segundo arco-íris branco. São Paulo: Iluminuras, 2010. p. 227-248.

. Os melhores poemas de Haroldo de Campos.

Selección de Inês Oseki- Dépré. São Paulo: Global, 2000. 
. Transluciferação Mefistofaústica. In:

Deus e o Diabo no Fausto de Goethe. São Paulo: Perspectiva, 1981. Pp. 179-209.

COSTA, H. Revisão: dinâmica de Haroldo de Campos na Cultura Brasileira. O Eixo e a Roda. Revista de Literatura Brasileira. Dossiê 50 anos de Poesia Concreta. 2006. p. 39-53. Disponível: [http://www. letras.ufmg.br/poslit/08_publicacoes_txt/er_13/er13_hc.pdf. Acesso: 05/05/11.

COSTA LIMA, L. O segundo arco-íris branco de Haroldo de Campos. In: DICK, A. (Org.). Signâncias: reflexões sobre Haroldo de Campos. São Paulo: Risco Editorial, 2010. p. 234-241.

FOLHA DE S. PAULO. Intelectuais ainda duvidam da psicanálise. Ilustrada. Folha de São Paulo. 22 set. 1989. p. 12.

GUINSBURG, J. "Entre a impressão e o inapreensível". Entrevista realizada por Gênese Andrade. In: DICK, A. (Org.). Signâncias: reflexões sobre Haroldo de Campos. São Paulo: Risco Editorial, 2010. Pp. 116-146.

JAKOBSON, R. On linguistic aspects of translation (1959). In: The Translation Studies Reader. Editado por L. Venuti). London; New York: Routledge, 2004. p. 138-143.

PORTELA, M. Haroldo de Campos (1929-2003): a estrutura paronomásica do universo. Inédito, 2003.

PREMinger, A., BRogan, T.V. F. (Ed.). The New Princeton Encyclopedia of Poetry and Poetics. Princeton: Princeton University Press, 1993.

Recebido em 31/03/2013.

Aprovado em 17/10/2013. 